\title{
Music as a vehicle for reducing HIV stigma and increasing access to testing in rural Uganda:A quasi- experimental, mixed-methods study
}

\begin{abstract}
Background: New HIV infections in Uganda rose by 21 percent in between the years of 2003 and 2013. Since 2014, the Global Livingston Institute has been working with community partners to produce the "iKnow" Concert Series in rural Uganda. This annual free concert series offers various musical acts featuring performers who come together to launch a three-pronged approach: (1) Use celebrities to stress that people can live a long, healthy life while HIV positive thereby decreasing stigma surrounding the disease; (2) distribute free condoms and teach people how to use them; and (3) offer free, on-site HIV testing, counseling, and treatment services. This study seeks to assess the familiarity and opinions of community members in Kabale regarding the "iKnow" Concert Series, as well as gain a deeper understanding of HIV-related knowledge and stigma in this region. We hypothesize that the concert is an effective intervention to increase knowledge and reduce stigma surrounding HIV in rural Uganda.
\end{abstract}

Methods: A quasi-experimental, mixed-methods design was used to conduct semistructured interviews. These interviews included survey questionnaires assessing personal HIV knowledge and stigma, as well as open-ended questions to allow for additional discussion.

Results: A total of 202 interviews were conducted. The mean total HIV/AIDS Knowledge score was 9.4 out of 11 and the Mean total HIV-related stigma score was 32.4 out of 90 . A multivariable linear regression analysis was run to predict HIV-related stigma and HIV/ AIDS Knowledge from gender, age, employment status, religion and education. These variables statistically predicted a significant association with reduced stigma and level of education $\mathrm{F}(5,196)=4.54, \mathrm{p}<0.0005, \mathrm{R} 2=0.102$ and higher levels of education being associated with reduced stigma $\mathrm{F}(5,196)=2.66, \mathrm{p}<0.0005$, R2 0.063. All 5 variables added to the prediction, $\mathrm{p}<.05$.

Conclusion: Education level is significantly associated with reduced negative attitudes and beliefs towards people living with HIV/AIDS (PLWHA). The results suggest that those who report having completed High School and higher, score almost 6 points lower of the stigma scale, on average. This study informs our efforts to increase accessibility to testing and services for rural communities while also reducing stigma and educating participants at the concert on disease prevention and treatment.
Volume 3 Issue 6 - 2019

Jessica Adams,' Julius Niringiyimana, ${ }^{2}$ James Michael Van Leeuwen, ${ }^{1,3}$ Andrew Ward,' Rumbi Gumbie,' Thomas Karrel'

'Global Livingston Institute, USA

2 Makerere University, Uganda

${ }^{3}$ University of Colorado -Denver, USA

Correspondence: James Michael Van Leeuwen, University of Colorado Denver, 300 I Brighton Boulevard Suite 2662 Denver, Colorado 80216, USA, Email Jamie@globallivingston.org

Received: October 30, 2019 | Published: November 19, 2019

\section{Introduction}

Once touted as Africa's HIV success story, Uganda saw a sharp decline in its national HIV prevalence rate from a high of 18 percent in the early 1990s to 6 percent in 2004. ${ }^{1}$ This trend then reversed itself rising to 7.2 percent in 2012 (United Nations International Children's Fund. ${ }^{2}$ As of 2016, the HIV prevalence rate of adults age 15-49 in Uganda stands at 6.5 percent. ${ }^{3}$ Prevalence rates have been impacted by the gradual increase in the number of people receiving antiretroviral therapy (ART). However, the number of new HIV infections rose by 21 percent in between the years of 2003 and $2013 .{ }^{4}$

The cause of the recent rise in HIV infection rates appears to be multi-factorial. Experts have attributed the rise of infection rates to complacency with regard to sexual behavior now that the extreme fear surrounding HIV that was present in the 1990s seems to have subsided, sluggish implementation of evidence-based prevention strategies such as male circumcision, lack of access to ARTs, and persistently high levels of HIV-related stigma.
Numerous studies indicate that stigmatizing attitudes towards people living with HIV have an impact on HIV testing, treatment, care and social support received by affected individuals..$^{5-9}$ In Uganda, a large scale-up in voluntary counseling and HIV testing services has been cited as a key element in the national HIV prevention strategy. However, studies have demonstrated that HIV-related stigma has a negative impact on the uptake of voluntary HIV counseling and testing. ${ }^{5}$

Significant correlation between poor knowledge regarding HIV and increased HIV stigma has been reported at length in the literature..$^{10}$ This is compounded by a demonstrated lack of education where 68 percent of students in primary school are estimated to drop out before reaching the last grade ${ }^{11}$ and an environment where a lack of formal address system leads to issues in identifying individuals and communities that would benefit from HIV services. Almost half of the Ugandan population is made up of children aged $0-14$, and approximately half of those aged 5-14 have jobs, which limits their opportunities to learn about safe sex and disease prevention through traditional vehicles such as school. ${ }^{12}$ 
Lifson et al. ${ }^{10}$ call for stigma reduction programs that address knowledge gaps and build on community-based attitudes showing compassion for people living with HIV. Chan \& Tsai ${ }^{13}$ recommend complementary strategies to engage young, single adults in order to achieve universal testing.

\section{Attitudes toward HIV and homosexuality}

Sexuality has been a polarizing topic in Uganda for that past three decades. The Ugandan parliament passed an Anti-Homosexuality bill in 2014, along with two other laws, devised to address sexual behavior deemed to be dangerous and abnormal. Although there has been a noted mobilization of anti-homosexuality rhetoric across Africa, Uganda has been in the spotlight largely due to moves initiated in 2009 by Ugandan Member of Parliament David Bahati to impose the death penalty on certain acts of homosexuality. ${ }^{14}$ It is argued that the seeds for the current state of affairs were actually planted in British Colonial times and have been further inflamed by Christian evangelicals from the United States. ${ }^{15,16}$

Today, anti-homosexual activists have successfully framed the homosexual person as an imminent threat who poses a serious moral danger to society. ${ }^{17}$ Criticisms of homosexuality are deeply entangled with growing disapproval of political and economic conditions and a belief that homosexuals operate in conjunction with Western norms that are both threatening and "un-African". ${ }^{17}$ These attitudes are also intertwined with those surrounding the issue of HIV. The President's Emergency Plan for AIDS Relief (PEPFAR), first authorized in 2003, earmarked billions of dollars in United States federal funding to promote HIV treatment and prevention worldwide. One-third of PEPFAR funding was set aside to support moral abstinence and faithfulness programs emphasizing personal accountability of the individual rather than the state, kin group, or community. ${ }^{18}$ Such policies have now been shown to have contributed to stigmatizing beliefs surrounding the disease since it has resulted in many people believing that disease contraction is a result of actions that are immoral or impure. ${ }^{18}$

Laws related to HIV testing also target gay men in particular, a population disproportionately burdened by HIV. The HIV/AIDS Prevention and Control Act of 2014 mandates disclosure of a person's mandatory HIV status and criminalizes HIV transmission and attempted transmission. ${ }^{14}$ The law effectively transforms HIV/AIDS from a medical issue to a legal issue and demonstrates a substantial amplification of state control over a person's sexual choices.

\section{Program description}

The Global Livingston Institute (GLI), working out of its base in Kabale, Uganda since 2009, collaborated with community leaders to identify HIV/AIDS as the predominant issue in their local area requiring immediate attention. Previous efforts to get youths in the region into testing and treatment by the World Health Organization, USAID, and other agencies were unsuccessful. This was largely attributed to HIV-related stigma.

Through working partnerships with community stakeholders, music was identified as a potential mechanism to deliver messages about sexual health and HIV given its cultural significance in rural communities throughout Uganda. These discussions were cross referenced with literature citing the valuable role of music in AIDS communication in Tanzania, a neighboring East African country. ${ }^{19}$
McClain ${ }^{20}$ describes how the Acholi communities of Northern Uganda "experience and perceive music as creating peaceful change through the community-identified roles of music as education, voice, memory, and healing". Bertrand and Rimon ${ }^{21}$ discuss success seen in Ghana following the implementation of the "Stop AIDS Love Life" campaign that involved engagement of community leaders, collaboration of many popular Ghanaian artists on a song encapsulating the program's main messages, and community mobilization efforts. Following those efforts, condom use among sexually active men increased from 10 percent to 34 percent while female condom use increased from 4 percent to 22 percent. ${ }^{21}$

McConnell ${ }^{22}$ poses that musical performances "may help build trust between health professionals and target communities while also facilitating information dissemination and public debate on sensitive health topics". Bekalu and Eggermont, ${ }^{23}$ in the course of their analysis of 23 AIDS songs used widely to aid prevention efforts in Ethiopia, suggest harnessing the use of song through a theory-based design for better outcomes. In the United States, Hill, Hallmark, et al. ${ }^{24}$ have also demonstrated success through implementation of their "Hip Hop for HIV Awareness" intervention aimed toward adolescents and youth in the Houston metropolitan area.

It is for all of these reasons that we believe an event-based HIV awareness and testing initiative can reduce stigma and increase acceptability of testing in rural Uganda. Entitled the "iKnow" Concert Series, this free annual concert offers a variety of musical acts featuring traditional artists from the community, well-known local stars, and international artists from around the world who come together to launch a three-pronged approach: (1) Attack stigma headon with local and national celebrities stressing that people can still live a long, healthy life while HIV positive; (2) distribute thousands of free condoms and teach people how to use them, destigmatizing their use and normalizing discussion; and (3) offer free, on-site rapid response testing, counseling, and linkage to care.

\section{Study objectives and hypothesis}

This study assesses the familiarity and opinions of community members in Kabale, Uganda regarding the "iKnow" Concert Series, and offers a deeper understanding of HIV-related stigma in this region in general. With the knowledge that HIV is highly stigmatized throughout sub-Saharan Africa, as well as other parts of the world, and that HIV-related stigma is known to impair testing and prevention efforts, the implications of this study are potentially widespread. It is necessary to ascertain the impact of this intervention on levels of HIVrelated stigma, particularly among the youth, who may hold promise for altering the course of Uganda's severe HIV epidemic. This study was conducted in collaboration with the Global Livingston Institute and Reach a Hand Uganda, who have worked with local musicians and community development organizations to produce the "iKnow" Concert in Kabale over the last four years. Ugandan social science research specialists from Makerere University also advised this project.

\section{Hypothesis}

The HIV Awareness "iKnow" Concert Series is a culturallyappropriate and effective intervention to increase knowledge and reduce stigma surrounding HIV in rural Uganda. 


\section{Study design and research methods}

\section{Study design}

Following approval from the Makerere University Institutional Review Board, a quasi-experimental, mixed methods design was used to recruit members of the Kabale community for one-on-one, semistructured interviews. These interviews included the delivery of preselected survey questionnaires, as well as open-ended questions that gave the participants an additional opportunity to discuss topics in further detail.

\section{Techniques}

Peer interviewers were employed and trained by the researchers in the protection of human subjects in the course of collecting data. This was done to facilitate conversation between researchers and participants who have similar cultural understandings. Participants were informed of the study's purpose and procedure. Informed consent was obtained prior to the interview. Survey and interview questions were read aloud in order to avoid issues with low literacy. Interviewers were fluent in both English and Rukiga.

\section{Data collection tools}

Following prudent deliberation by engaging local health professionals concerning which HIV-related stigma assessment tool to use for this study, the decision was made to utilize an instrument developed and tested in 2012 by John Ekwaru of the University of California, Berkeley. ${ }^{25}$ Incidentally, it is also the first tool to be specifically developed for use among youth in Uganda. This tool was developed with the appreciation of HIV-related stigma as a multidimensional construct. Measures of all three sub-dimensions of HIVrelated stigma (described as social distance, blame/victimization, and sympathy/care) are included in this tool. The 30-item tool was adapted from four other published HIV-related stigma assessment scales. Responses are scored from 0-3 along a Likert-scale that allows a respondent to choose from "Strongly Agree," "Agree," "Disagree," or "Strongly Disagree" with higher scores indicating higher levels of stigma toward HIV and a range of potential scores from 0 to 90 .

We also utilized a brief HIV Knowledge Assessment Tool modified by Kalichman and Simbayi ${ }^{26}$ that assesses knowledge about HIV over three dimensions: HIV casual contagion, HIV transmission/ prevention and HIV disease processes. These responses are simply "Yes", "No", or "Don't Know". They are scored 1 when correct and 0 if incorrect. An answer of "Don't Know" will be counted as incorrect. A higher score indicates a higher level of knowledge regarding HIV/ AIDS. This tool is an 11-item scale that was adapted from the 18 item HIV-KQ-18 published by Carey \& Schroeder, ${ }^{27}$ a tool that had been modified from an earlier 45 -item knowledge scale. ${ }^{28}$ Cumulative scores can range from 0 to 11 .

We requested demographic information such as age, gender, religion, employment, and education. Additional questions designed to assess respondents' familiarity with the "iKnow" Concert Series and how many times they have attended were included. This may help provide insight into what channels are most successful in promoting the concert series and its messages. Other open-ended questions that were added include community-specific questions assessing HIVrelated stigma, as well as questions designed to assess what other HIV-related activities are taking place in the selected communities and how/where people are receiving information about HIV.
A data collection program was designed that included all questionnaire and open-ended survey questions with the capability of exporting all completed data in Microsoft Excel format. This program was uploaded onto six laptops that were taken to Uganda solely for this purpose. Microphones were included to record all interviews.

\section{Data analysis}

Interview data were compiled using ATDMS software and exported to Microsoft Excel for analysis by the Policy \& Research Group in New Orleans, Louisiana. Data was analyzed using Stata 15 software to include an initial descriptive statistics memorandum, followed by a supplementary data analysis report of inferential statistics that investigate correlations between constructs identified in a set of six defined research questions. Regression models were used to estimate the magnitude and direction of the relationships between variables. Hypothesis tests were then utilized in order to determine if those relationships were statistically significant. Results were deemed significant if hypothesis test statistics indicate findings at the $\mathrm{p}<0.05$ level using a two-tailed t- or z-test. A thematic analysis was also used to examine the qualitative data collected.

\section{Results}

The following are descriptive statistics reported by our contracted research partner, Policy \& Research Group (email to author, December 18, 2018). Please note that all data is compiled from the Kabale sample size of 202 people.

\section{Descriptive analysis - demographics}

A total of 202 individuals were interviewed. The mean age of the sample was 29.1 years old $(\mathrm{SD}=11.6)$ ranging from 17 to 70 , with $138(68.3 \%)$ men (Table 1). The vast majority of the sample reported Christian as their religion $(\mathrm{n}=165,81.6 \%)$. Education for high school and above was $124(61.8 \%)$ however Uganda has an education index of 0.467 and ranks 153 out of 188 countries (UNDP, 2016). This index is formulated by calculating the mean average years of schooling (5.7) plus the expected years of schooling (10.0) divided by 2 . This means that to be considered educated on average a Ugandan is expected to have 10 years of schooling albeit the average schooling a Ugandan will receive is 5.7 years. This indicates that $99(49 \%)$ participants are educated while $58(50.9 \%)$ are uneducated.

\section{Descriptive analysis - HIV knowledge \& stigma}

The outcomes of the HIV/AIDS knowledge scale with overall mean score and three subscales are shown in Table 2. The overall HIV/AIDS knowledge mean score was 9.4 (out of 11) \pm 1.48 , and the scores for the three subscales were causal contagion $(2.4 \pm 0.37)$ transmission (5.2 \pm 0.92$)$ disease process $(1.8 \pm 0)$ According to the percentile of the HIV/AIDS Knowledge scale, participants displayed higher knowledge of how the disease is transmitted and the least knowledge of the disease process.

The outcomes of the HIV-related stigma scale with overall mean score are shown in Table 3. The overall HIV-Related stigma mean score was 32.4 (out of 90). In addition, a single question was asked to operationalize endorsing traditional beliefs. Only $5 \%$ of respondents have such beliefs.

\section{Factors associated with HIV-related stigma}

In the regression analysis it was found that level of education 
(High School graduate and above) is significantly associated with reduced negative beliefs and attitudes towards people living with HIV/AIDS (PLWHA) According to the model, completing high school is associated with a nearly three-point reduction in the stigma score. When the model is applied with knowledge as a measure, and stigma as the response variable, this corresponds with the hypothesis that a participant's level of HIV/AIDS knowledge is a factor that determines their attitudes and beliefs towards PLWHA. The results therefore indicate a strong statistically significant relationship between the knowledge scale score and the HIV stigma scale score. We can therefore hypothesize that that higher levels of HIV/AIDS knowledge are associated with reduced negative attitudes and beliefs towards PLWHA reduced negative attitudes and beliefs towards PLWHA.

Table I Demographic characteristics

\begin{tabular}{|c|c|c|}
\hline Characteristic & & \\
\hline Age & f & $\%$ \\
\hline $15-19$ & 29 & 14.3 \\
\hline $20-24$ & 66 & 32.7 \\
\hline $25-29$ & 38 & 18.8 \\
\hline $30-34$ & 24 & 11.9 \\
\hline $35-39$ & 15 & 7.4 \\
\hline $40-44$ & 5 & 2.5 \\
\hline $45-49$ & 7 & 3.5 \\
\hline $50+$ & 18 & 8.9 \\
\hline Total & 202 & 100 \\
\hline Gender & $f$ & $\%$ \\
\hline Female & 64 & 31.7 \\
\hline Male & 138 & 68.3 \\
\hline Total & 202 & 100 \\
\hline Religion & $f$ & $\%$ \\
\hline Catholic & 33 & 16.3 \\
\hline Christian & 165 & 81.7 \\
\hline Muslim & 3 & 1.5 \\
\hline None & I & 0.5 \\
\hline Total & 202 & 100 \\
\hline Education & f & $\%$ \\
\hline None & 12 & 5.9 \\
\hline $\begin{array}{l}\text { Some Primary Education } \\
\text { (PI-P6) }\end{array}$ & 43 & 21.3 \\
\hline
\end{tabular}

\begin{tabular}{lll} 
Table Continued & & \\
\hline Characteristic & & $\%$ \\
\hline Age & f & 14.9 \\
$\begin{array}{l}\text { Completed Primary } \\
\text { School (P7) }\end{array}$ & 30 & 8.9 \\
$\begin{array}{l}\text { Some Lower Secondary } \\
\text { Education SI-S3) }\end{array}$ & 18 & 13.9 \\
$\begin{array}{l}\text { Completed Lower } \\
\text { Secondary School (S4) }\end{array}$ & 28 & 7.9 \\
Graduated High School & 16 & 21.8 \\
$\begin{array}{l}\text { Some College } \\
\text { Associate's Degree }\end{array}$ & $\mathbf{1}$ & 0.5 \\
Bachelor's Degree & 10 & 5 \\
Total & $\mathbf{2 0 2}$ & 100.1 \\
$\begin{array}{l}\text { Current Employment } \\
\text { Status }\end{array}$ & $\mathbf{f}$ & $\%$ \\
Unemployed & 112 & 55.4 \\
Employed & 90 & 44.6 \\
Total & $\mathbf{2 0 2}$ & 100 \\
\hline
\end{tabular}

Table 2 HIV/AIDS-Related Knowledge

\begin{tabular}{llll}
\hline Variable(s) & $\begin{array}{l}\text { Maximum } \\
\text { point scale }\end{array}$ & Mean & $\begin{array}{l}\text { Standard } \\
\text { deviation }\end{array}$ \\
\hline $\begin{array}{l}\text { Overall HIV/AIDS } \\
\text { Knowledge }\end{array}$ & $\mathrm{II}$ & 9.4 & 1.48 \\
Casual Contagion & 3 & 2.4 & 0.37 \\
Transmission & 6 & 5.2 & 0.92 \\
Disease Process & 2 & 1.8 & 0 \\
\hline
\end{tabular}

Table 3 HIV-Related Stigma

\begin{tabular}{lll}
\hline Variable & $\begin{array}{l}\text { Maximum } \\
\text { point scale }\end{array}$ & Mean \\
\hline $\begin{array}{l}\text { Overall HIV/Aids } \\
\text { Related Stigma Scale }\end{array}$ & 90 & 32.4 \\
\hline
\end{tabular}

\section{Factors associated with concert awareness/attendance}

Of the total 202 respondents, 37 percent affirm that they have heard of the "iKnow" Concert Series and 22 percent report attending one of the events. Linear regression analysis established that a significant negative relationship between awareness indicator and stigma scale score, $F(6,195)=5.32, p=0.0000$, no significant relationship between attendance indicator and stigma scale score, $F(6,175)=$ $3.84, p=0.0012$ and a borderline significant and negative relationship between frequency of attendance and stigma scale score, $F(6,195)=$ 4.63, $p=0.0002$.

\section{Discussion of data-driven research questions}

A primary goal within this research initiative included determining whether and to what extent correlations existed in six key areas. After 
collecting and analyzing the data, several significant relationships between levels of stigma and HIV knowledge emerged. In three instances, there was no significant relationship discovered. Each research question and the corresponding findings are discussed below:

I. Do individuals who report having knowledge of or having attended the concert express fewer negative attitudes and beliefs regarding people living with HIV/AIDS-related (i.e. stigma) than individuals who report no knowledge/attendance?

Results indicate that respondents who report having awareness of the "iKnow" Concert Series score nearly an average of four points lower on the stigma scale than respondents unfamiliar with this initiative. Results also suggest that, for each day that a respondent claims to have attended one of the concerts, their stigma scale would be reduced by close to two points.

II. Do individuals who report having knowledge of or having attended the concert have higher levels of HIV/AIDS-related knowledge than individuals who report no knowledge/attendance of the concerts?

There is no significant relationship noted between awareness/ attendance of the concerts and knowledge scale score. This would therefore indicate that most of the people attending the concert already had relatively higher degrees of HIV knowledge than the general populous.

III. Do individuals who report endorsing traditional beliefs have fewer negative attitudes and beliefs regarding people living with HIV/AIDS (i.e. stigma) than individuals who do not endorse traditional beliefs?

There is no significant relationship noted between the endorsement of traditional beliefs and stigma scale score. This is remarkable, as a significant body of research indicates that in other parts of SubSaharan Africa traditional beliefs often tend to be directly associated with higher levels of stigma. ${ }^{26}$

IV. Do individuals who report endorsing traditional beliefs have higher levels of HIV/AIDS-related knowledge than individuals who do not endorse traditional beliefs?

There is no significant relationship noted between the endorsement of traditional beliefs and knowledge scale scores. Similar to the previous question, this is notable in that it countervails what existing literature suggests regarding traditional beliefs and HIV knowledge.

V. Is higher HIV/AIDS-related knowledge associated with fewer negative attitudes and beliefs regarding people living with HIV/ AIDS (i.e. stigma)?

Results demonstrate a strong and significant inverse relationship between knowledge and stigma. This is consistent with established literature establishing that higher levels of HIV/AIDS-related knowledge correspond to lower levels of HIV/AIDS-related stigma. The data suggest that a one-unit increase in knowledge scale scores correspond to an approximately two-unit decreased in stigma scale scores

VI. Are respondents self-reported age, gender, education level, employment status, or religion related to HIV/AIDS-related knowledge or HIV/AIDS-related stigma?

Overall education is shown to be negatively related to stigma with respondents who report having completed high school scoring approximately 5-6 points lower than those who report not attaining a high school education. Data also demonstrates that respondents who self-report as Christian scored approximately 0.6 points better on the knowledge scale scores than those who identified as other religions, including those who specified themselves as Catholic.

\section{Limitations}

Although the study was designed for the interviewers to be able to move freely throughout the community and participate in snowball sampling, the laptops being used for the interviews were found to lose charge within just a few hours and required a power source. Additionally, use of the microphones were found to cause the laptops to lose charge substantially faster and this backup method of recording data had to be largely abandoned. There were a limited number of power sources within the communities available for the interviewers to use for charging of the data collection devices. Therefore, the interviewers were forced to be more stationary than was originally planned. We were able to set up in two different locations in the community during the two separate days of data collection. One location was at the concert site during preparation where generators were available. Loud music playing also limited clear communication efforts.

Feedback was requested from the Ugandan peer interviewers regarding the process and ease of utilizing the selected questionnaires. They expressed difficulties with translation of some words, namely "stigma" and "promiscuous". Ugandans also had some difficulties gauging their answers on a Likert scale and requested an "I don't know" option that was not available on the questionnaires. Official edits to the data collection tools could not be made in the field due to the use of pre-programmed laptops.

Final sample size was 202. This limited our ability to establish significant relationships and findings. Data collected are crosssectional. Relationships that are noted in the study may, in fact, be a result of unperceived factors that were not included in the statistical models.

\section{Sampling technique \& generalizability}

A sample size of 200 was selected largely due to the mixed methods design of the study that includes the collection of qualitative data through the use of structured interviews. Each participant completed the brief survey tools, in addition to continuing on to the semi-structured interviews where they had an opportunity to elaborate on their opinions regarding the subject matter. Although there are no defined rules for sample size in qualitative research, it is generally agreed that sample sizes larger than 30 and less than 500 are appropriate for most research. ${ }^{29}$ Feasibility of sample size is also determined by the availability of factors such as time, human resources, transportation, and funding. A sample size of approximately 200 (the specific total was 196) for the quantitative portion of the study was able to demonstrate results with a margin of error that equals $7 \%$ at a $95 \%$ confidence interval. This is an acceptable margin of error used by survey researchers. ${ }^{30}$ The population estimate uses the most recent available figures assuming a total population in Kabale District of $490,227 .^{31}$

The small sample size is modest resulting in a lack of statistical power needed to confirm generalizability of findings. However, small sample research is critical for collecting data associated with vulnerable populations who are often times small in number and 
difficult to recruit by definition. ${ }^{32}$ Similar issues arise when attempting to assess community-level interventions that are designed to reach study participants at multiple levels ${ }^{33}$ as is the "iKnow" Concert Series. Taken within the context of the development of intervention solutions targeting specific populations, one could also question the value generalizability and its importance for those who may not be attempting to intervene in populations other than from whom the sample was drawn. ${ }^{32}$ In this case, generalizability of results is a goal for continuing research and future sample sizes will be larger.

\section{Conclusion}

Overall high levels of knowledge and low levels of stigma were seen throughout the sample population. The distribution of the scale scores associated with the HIV/AIDS-related Knowledge questionnaire is skewed. No respondents scored lower than 6. This suggests that, for this sample, the test may be too easy.

Traditional beliefs explain virtually no variation in either knowledge or stigma scales. Awareness of and attendance at the "iKnow" Concert Series explains essentially no variation noted in the knowledge scale. However, awareness and frequency of attendance demonstrate approximately three and two percent of variation in the stigma scale, respectively.

We believe that this data reflects an encouraging foundation on which to build as we continue to evaluate HIV knowledge and stigma over time and in other regions as the project expands. Next steps include replicating the study on a larger scale as a means of corroborating our preliminary findings which indicate the "iKnow" Concert Series may serve as an effective HIV stigma reduction intervention in this rural community. These initiatives are critical as HIV stigma reduction efforts are urgently needed in Uganda and beyond.

\section{Acknowledgments}

We gratefully acknowledge that the research for this paper was financially supported by Odyssey House Louisiana, Inc. Global Livingston Institute and Reach a Hand Uganda provide continued support to this work and the local communities in Uganda have allowed for the opportunity to collaborate on such critical projects. Special thanks to Makerere University for providing ethical clearance and ongoing research guidance.

\section{Conflicts of interest}

The author declares no conflicts of interest.

\section{Funding}

None.

\section{References}

1. Ahaibwe G. Halting and reversing the spread of HIV/AIDS in Uganda: President Museveni publicly tests for HIV. 2013.

2. UNESCO. $42 \%$ of African school children will drop out before the end of primary education. United Nations International Children's Fund [UNICEF]. Uganda - Statistics. 2011.

3. UNAIDS. AIDSinfo. 2017.

4. Uganda AIDS Commission [UAC]. National HIV and AIDS priority action plan 2015/2016- 2019/2020. An AIDS free Uganda, My responsibility! Uganda AIDS Commission. Republic of Uganda. 2015.
5. Ayiga N, Nambooze H, Nalugo S, et al. The impact of HIV/AIDS stigma on HIV counseling and testing in a high HIV prevalence population in Uganda. Afr Health Sci. 2013;13(2):278-286.

6. Emenyonu NI. Barriers to HIV care in rural Uganda. Doctoral dissertation. 2012

7. Kuteesa MO, Wright S, Seeley J, et al. Experiences of HIV-related stigma among HIV-positive older persons in Uganda -- A mixed methods analysis. Journal of Social Aspects Of HIV/AIDS Research Alliance. 2014;11(1):126-137.

8. Neuman M, Obermeyer CM. Experiences of stigma, discrimination, care and support among people living with HIV: a four country study. AIDS Behav. 2013;17(5):1796-1808.

9. Takada S, Weiser SD, Kumbakumba E, et al. The Dynamic Relationship Between Social Support and HIV-Related Stigma in Rural Uganda. Ann Behav Med. 2014;48(1):26-37.

10. Lifson A, Deissie W, Tadesse A, et al. BMC International Health and Human Rights. 2012;12(6).

11. UNESCO. $42 \%$ of African school children will drop out before the end of primary education. United Nations International Children's Fund [UNICEF] (2013). Uganda - Statistics. 2011

12. The Republic of Uganda. The HIV and AIDS Uganda country progress report 2014. 2015

13. Chan BT, Tsai AC. HIV stigma trends in the general population during antiretroviral treatment expansion: analysis of 31 countries in sub-Saharan Africa, 2003-2013. J Acquir Immune Defic Syndr. 2016;72(5):558-564.

14. Vorhölter J. Homosexuality, pornography, and other 'modern threats' - The deployment of sexuality in recent laws and public discourses in Uganda. Critique of Anthropolog. 2017;37(1):93-111.

15. Han E, Omahoney J. British colonialism and the criminalization of homosexuality. Cambridge Review of International Affairs. 2014;27(2):268-288.

16. Nyanzi S, Karamagi A. The social-political dynamics of the antihomosexuality legislation in Uganda. Empowering women for gender equity. 2015;29(1):24-38.

17. Boyd L. The Problem with freedom: Homosexuality and human rights in Uganda. Anthropological Quarterly. 2013;86(3):697-724.

18. Boyd L. Preaching prevention: born-again Christianity and the moral politics of AIDS in Uganda. USA: Ohio University Press; 2015.

19. Bastien S. Reflecting and shaping the discourse: the role of music in AIDS communication in Tanzania. Soc Sci Med. 2009;68(7):1357-1360.

20. McClain Opiyo L. Music as education, voice, memory, and healing: Community views on the roles of music in conflict transformation in Northern Uganda. African Conflict and Peacebuilding Review. 2015;5(1):41-65.

21. Bertrand J, Rimon J. Stop AIDS love life in Ghana "shatters the silence". Communication Impact. Number. 2003;15.

22. McConnell B. Music and health communication in The Gambia: A social capital approach. Soc Sci Med. 2016;169:132-140.

23. Bekalu M, Eggermont S. Aligning HIV/AIDS communication with the oral tradition of Africans: a theory-based content analysis of songs' potential in prevention efforts. Health Commun. 2015;30(5):441-450.

24. Hill M, Hallmark, C. McNeese M. Hip hop for HIV awareness: using hip hop culture to promote community-level HIV prevention. Sex Educatio. 2013;14(2):129-143. 
25. Ekwaru JP. The effect of abstinence, being faithful to one partner, and condom use $(A B C)$ messages on HIV infection among youth in Uganda (Doctoral dissertation). 2014.

26. Kalichman SC, Simbayi L. Traditional beliefs about the cause of AIDS and AIDS-related stigma in South Africa. AIDS Car. 2004;16(5):572580

27. Carey MP, Schroder KEE. Development and psychometric evaluation of the brief HIV Knowledge Questionnaire. AIDS Educ Prev. 2002;14(2):172-182.

28. Carey MP, Morrison-Beedy D, Johnson BT. The HIV-Knowledge Questionnaire: Development and evaluation of a reliable, valid, and practical self-administered questionnaire. AIDS and Behavior. 1997;1(1):61-74.
29. Abranovic WA. Statistical Thinking and Data Analysis for Managers. Reading, MA: Addison-Wesley.1997.

30. DataStar, Inc What Every Research Should Know About Statistical Significance. 2010.

31. Langan C, Farmer J. Profile of Kabale District, Uganda. Alter: Alternative Investments in Ecosystems for Poverty Alleviation. 2014.

32. Trickett EJ, Beehler S, Deutsch C, et al. Advancing the science of community-level interventions. Am J Public Health. 2011;11:14101419 .

33. Etz KE, Arroyo JA. Small sample research: Considerations beyond statistical power. Prev Sci. 2015;16(7):1033-1036. 